\title{
Economic cost and quality of life of family caregivers of schizophrenic patients attending psychiatric hospitals in Ghana
}

Yaw Nyarko Opoku-Boateng 1,3, Irene A. Kretchy², Genevieve Cecilia Aryeetey ${ }^{3}$, Duah Dwomoh ${ }^{4}$, Sybil Decker ${ }^{5}$, Samuel Agyei Agyemang ${ }^{3}$, Yesim Tozan ${ }^{6}$, Moses Aikins ${ }^{3}$ and Justice Nonvignon ${ }^{3 *}$

\begin{abstract}
Background: Low and middle income countries face many challenges in meeting their populations' mental health care needs. Though family caregiving is crucial to the management of severe mental health disabilities, such as schizophrenia, the economic costs borne by family caregivers often go unnoticed. In this study, we estimated the household economic costs of schizophrenia and quality of life of family caregivers in Ghana.

Methods: We used a cost of illness analysis approach. Quality of life (QoL) was assessed using the abridged WHO Quality of Life (WHOQOL-BREF) tool. Cross-sectional data were collected from 442 caregivers of patients diagnosed with schizophrenia at least six months prior to the study and who received consultation in any of the three psychiatric hospitals in Ghana. Economic costs were categorized as direct costs (including medical and non-medical costs of seeking care), indirect costs (productivity losses to caregivers) and intangible costs (non-monetary costs such as stigma and pain). Direct costs included costs of medical supplies, consultations, and travel. Indirect costs were estimated as value of productive time lost (in hours) to primary caregivers. Intangible costs were assessed using the Zarit Burden Interview (ZBI). We employed multiple regression models to assess the covariates of costs, caregiver burden, and QoL.
\end{abstract}

Results: Total monthly cost to caregivers was US\$273.28, on average. Key drivers of direct costs were medications (50\%) and transportation (27\%). Direct costs per caregiver represented 31\% of the reported monthly earnings. Mean caregiver burden (measured by the ZBI) was 16.95 on a scale of $0-48$, with $49 \%$ of caregivers reporting high burden. Mean QoL of caregivers was 28.2 (range: 19.6-34.8) out of 100. Better educated caregivers reported lower indirect costs and better QoL. Caregivers with higher severity of depression, anxiety and stress reported higher caregiver burden and lower QoL. Males reported better QoL.

Conclusions: These findings highlight the high household burden of caregiving for people living with schizophrenia in low income settings. Results underscore the need for policies and programs to support caregivers.

Keywords: Economic burden, Quality of life, Caregiving, Schizophrenia, Ghana

\footnotetext{
*Correspondence: jnonvignon@ug.edu.gh

${ }^{3}$ Department of Health Policy, Planning and Management, School of Public

Health, College of Health Sciences, University of Ghana, Legon, Ghana

Full list of author information is available at the end of the article
} 


\section{Background}

Mental illness accounts for about 32\% of years lived with disability (YLD) and about 13\% of disabilityadjusted life-years (DALYs), a percentage that equals that of cardiovascular and circulatory diseases [1]. Schizophrenia is a severe mental disorder characterized by significant distortions in thinking and perception, accompanied by an exhibition of inappropriate emotions [2, 3]. Schizophrenia alters individuals' perception of reality, often making them think and act in ways that are strange or abnormal by socially sanctioned standards. The World Health Organization (WHO) estimates that about 21 million people suffer from schizophrenia globally [4]. It is estimated that $13 \%$ of Ghanaians suffer from at least one form of mental or substance abuse disorder and that about $32 \%$ of all mental health cases managed in the country's three psychiatric hospitals are schizophrenic [5].

Caregiving plays a significant role in the management of schizophrenia. For example, the WHO indicates that globally up to $90 \%$ of schizophrenic patients live with their families [6]. In many low and middle income countries (LMICs), the social structure of families and economic hardship impede the use of paid caregivers. Other health systems challenges, such as inadequate health personnel and poor infrastructure, further increase the burden of caring for people with mental disorders.

A key provision of Ghana's 2012 Mental Health Act (Act 846 ) is to de-institutionalize mental health care (i.e., provide community-based care for people with mental disorders) in order to decongest the three psychiatric hospitals. The role of caregivers in this community-based approach is crucial since family interactions influence treatment outcomes and relapse rates [7]. However, as in other LMICs, family caregivers of schizophrenic patients in Ghana bear significant economic, psychological and social burdens, which are often unaccounted for in interventions [8-15]. For instance, the time required to care for schizophrenic patients affects the productivity of caregivers, often limiting their participation in the labor force, which has economic implications for the family. Families also incur substantial medical and non-medical costs associated with the management of the condition, which may lead to financial impoverishment. In addition, caring people with mental disorders places significant psychological burden on caregivers and has been shown to negatively affect caregivers' quality of life (QoL) $[16,17]$. Other social burdens that families bear include stigma, which affects the social support that is much needed for such patients and their families.

Although Ghana has a high burden of mental illness, few studies have examined the burden of mental illness in general-and schizophrenia in particular-on unpaid family caregivers. In this study, we sought to address this gap by estimating the economic burden and quality of life of family caregivers of schizophrenic patients in Ghana.

\section{Methods \\ Study setting}

The study was undertaken at the three psychiatric hospitals in Ghana: Accra, Pantang and Ankaful. Accra Psychiatric Hospital is a 600-bed hospital commissioned in 1906 as the first psychiatric hospital in Ghana and is located in the Greater Accra Region. Established in 1975 with a bed capacity of 500, the Pantang Psychiatric Hospital is situated in Pantang, also in the Greater Accra Region. Ankaful Psychiatric Hospital, which was built in 1965, is a 350-bed hospital located near the coastal town of Cape Coast in the Central Region of Ghana that serves patients from the Central, Western and Ashanti regions of Ghana and some neighbouring countries. All the hospitals are located in the southern part of the country and serve the country's population of approximately 25 million [18].

\section{Study population and sample size}

The study population comprised family (primary) caregivers of schizophrenic patients reporting to the outpatient department at each study site. Based on Cochran [19], the sample size was calculated using the formula below:

$$
n_{0}=(\text { Deff }) \frac{\left(Z_{\frac{\alpha}{2}}\right)^{2} p(1-p)}{e^{2}}
$$

Where $n_{0}$ is the minimum required sample size; $Z^{2}$ is an abscissa of the curve that cuts off an area $\propto$ at the tail (1 $-\alpha$ equals the desired confidence level, i.e., 95\%); $e$ is the desired level of precision; $p$ is the estimated proportion of schizophrenic patients that is present in the population, which was assumed to be $50 \%$ since the current proportion is unknown; and Deff is the design effect. For a $95 \%$ confidence interval, $Z_{\frac{\alpha}{2}}$ is 1.96 and the level of precision $e$ (margin error for the study) $\pm 5 \%$. Assuming a design effect of 1.03 , we computed a minimum sample size of.

$$
n_{0}=1.03 * \frac{1.96^{2} \times 0.5 \times 0.5}{0.05^{2}}=395.684 \approx 396 .
$$

Assuming a $90 \%$ response rate, we estimated a minimum sample size of 440 patients. We computed the sample size required in each facility using probability proportionate to size (PPS) of number of schizophrenic patients (Table 1). 
Table 1 Sample size for study sites

\begin{tabular}{llll}
\hline Hospital & Number of patients & Sample size & Percentage \\
\hline Accra & 11,256 & 228 & 51.8 \\
Pantang & 6780 & 138 & 31.4 \\
Ankaful & 3660 & 74 & 16.8 \\
Total & 21,696 & 440 & 100.0 \\
\hline
\end{tabular}

In each hospital, folders of patients diagnosed with schizophrenia at least six months preceding the study were sorted and reviewed using criteria outlined in the $10^{\text {th }}$ revision of the International Statistical Classification of Diseases and Related Health Problems (ICD-10), and primary caregivers who attended the hospital with the patients identified and interviewed. Accompanying relatives who were not the primary caregivers were excluded. Given that many patients presenting for outpatient services were unaccompanied, accompanying primary caregivers were recruited until the required sample size for the particular facility was met.

\section{Data collection and tools}

Data were collected using a structured, intervieweradministered questionnaire with closed- and open-ended questions. The questionnaire elicited information on caregivers' sociodemographic characteristics, direct health care costs (medical and non-medical costs) and indirect costs (i.e. productivity losses) to caregivers.

\section{Variables}

We used a cost of illness analysis approach. Costs were analysed from the caregiver perspective and included costs incurred during the month preceding the data collection. All costs were computed in United States Dollars (US\$) (3.9 Ghanaian Cedi (GHS) $\approx 1$ US\$). Costs were not adjusted for inflation. Costs were categorized into direct, indirect and intangible costs. Direct costs were further grouped into medical and non-medical costs. Medical costs included the costs of drugs, consultations, laboratory investigations and diagnostics and other therapies. Non-medical costs included the cost of travel to and from hospital, food costs incurred by the caregiver during the treatment period, accommodation costs if the caregiver travelled with the patient away from home, and miscellaneous costs such as telephone costs related to medical care. The sum of medical and non-medical costs constituted the direct costs.

Indirect costs were estimated using the national daily minimum wage of US\$ 2.0 per day (May 2016) for caregivers in the formal sector and a local daily agricultural wage rate of US\$ 4.50 was used for caregivers working in the informal sector. Unemployed caregivers were considered part of the informal sector. Travel time was calculated by adding the total number of hours spent travelling to and from the hospital. Waiting time constituted the total time spent waiting for and receiving treatment (i.e., from the time the caregiver and patient arrived at the hospital to the time they left the hospital). The time used for other caregiving activities, such as household activities and leisure, was also calculated and included in the indirect costs. Total indirect cost was calculated as the product of the sum of total time spent on personal care for patient, transport and waiting for health care, other household activities for the patient (in hours) and the respective (hourly) wage rate. Total economic cost constituted the sum of direct and indirect costs.

Intangible costs (sometimes referred to as caregiver burden) were assessed using the 12-item Zarit Burden Interview (ZBI) tool developed by Bedard et al. [20], which comprises items assessing stress, pain, anxiety and depression. The intangible cost was analysed by summing the scores for all 12 items for each respondent. The overall score ranges between 0 and 48 . Scores were then categorized as low burden (0-16) or high burden (17-48).

Quality of life was assessed using the abridged WHO Quality of Life (WHOQOL-BREF) tool. The WHOQOLBREF comprises 26 items: two items assessing the overall quality of life and general health; and 24 assessing satisfaction in four main domains - seven items on physical health, six items on psychological health, three items on social relationships, and eight items on environmental health. Each item was rated on a scale of 1 to 5 with 1 being the lowest and 5 being the highest QoL. The mean score of items within each domain was used to calculate the domain mean. The mean score for each domain was then multiplied by 4 (four) to make it comparable with the full WHOQOL tool (WHOQOL-100) [21]. The scores were scaled in a positive direction so that a higher score indicated a higher QoL.

Other variables used in the analysis included Age (in years) as at last birthday; Sex measured as a dummy, 1 for male and 0 for female; Marital status: Married (1), single (0); Proximity of residence from health facility visited; 1 for far (living more than 30 min from facility, by typical mode of transport used) and 0 for close; Caregiver's highest level of education: no education (0), primary/junior high school (i.e. basic education or equivalent) (1), secondary (2) and tertiary (3); Caregiver's employment status: unemployed (0), self-employed (1), private sector (2), public sector (3), student/apprentice (4); Caregivers were asked whether other members of the family spent time taking care of the patient (other family support): yes (1), no (0); and Caregiver's mental health status (i.e. depression, anxiety, stress). Mental health status was assessed using the Depression Anxiety 
Stress Scale (DASS-21), which comprises of three subscales: Depression (DASS-D), Anxiety (DASS-A), and Stress (DASS-S). Responses on each item ranged from 0 (did not apply to me at all) to 3 (applied to me very much).

Reliability of the QoL and Zarit burden scale was assessed using Cronbach's alpha. With the exception of the depression sub-scale of the DASS-21 and the social sub-scale of the WHOQOL, the Cronbach alpha values fell within the acceptable range of alpha values $(0.70$ to 0.95) [22-24] (Table 2).

\section{Data analysis}

Descriptive statistics (mean, standard deviation) of study variables are presented in Table 3. Two sets of multivariate linear regression models were fitted to assess factors associated with economic costs and QoL. The first set of models had direct and indirect costs as dependent variables, and demographic and socioeconomic factors (e.g., age, sex, marital status, proximity of residence to facility, highest education level and employment status) as explanatory variables. The second set of models had the four domains of QoL as dependent variables. Explanatory variables comprised direct costs, indirect costs, Zarit burden scores, time and duration of care provided, mental health indices (anxiety, depression, stress). The models also controlled for caregivers' sociodemographic characteristics. A final model was fitted to investigate the covariates of caregiver burden (measured by the ZBI score).

\section{Results}

\section{Background characteristics of caregivers}

Caregivers' sociodemographic characteristics are summarized in Table 3. Caregivers' mean age was 47 years $(45 \%$ were aged 30-49 years and 37\% aged 50-69 years). Fifty-seven percent of caregivers were female and $66 \%$

Table 2 Internal consistency of the mental health status, quality of life, and Zarit burden indices

\begin{tabular}{lll}
\hline Domain & Number of items & Cronbach's alpha \\
\hline Mental health status & & \\
Depression & 7 & 0.67 \\
Anxiety & 7 & 0.80 \\
Stress & 7 & 0.83 \\
Quality of life & & \\
Physical & 7 & 0.82 \\
Psychological & 6 & 0.77 \\
Social & 3 & 0.56 \\
Environmental & 8 & 0.81 \\
Zarit burden index & 12 & 0.83 \\
\hline
\end{tabular}

Table 3 Socio-demographic characteristics of caregivers $(N=444)$

\begin{tabular}{|c|c|c|}
\hline Characteristic & Number & $(\%)$ \\
\hline \multicolumn{3}{|l|}{ Sex } \\
\hline Male & 193 & 43.5 \\
\hline Female & 251 & 56.5 \\
\hline \multicolumn{3}{|l|}{ Age } \\
\hline$<20$ & 3 & 0.7 \\
\hline $20-29$ & 51 & 11.5 \\
\hline $30-39$ & 95 & 21.4 \\
\hline $40-49$ & 103 & 23.2 \\
\hline $50-59$ & 89 & 20.0 \\
\hline $60-69$ & 76 & 17.1 \\
\hline$>69$ & 27 & 6.1 \\
\hline \multicolumn{3}{|l|}{ Marital Status } \\
\hline Married & 294 & 66.2 \\
\hline Single & 150 & 33.8 \\
\hline \multicolumn{3}{|l|}{ Religion } \\
\hline Christian & 393 & 88.5 \\
\hline Muslim & 45 & 10.1 \\
\hline Traditionalist & 2 & 0.5 \\
\hline Other & 4 & 0.9 \\
\hline \multicolumn{3}{|l|}{ Educational Level } \\
\hline No education & 50 & 11.3 \\
\hline Primary & 146 & 32.8 \\
\hline Secondary & 149 & 33.6 \\
\hline Tertiary-Graduate/Post Graduate & 99 & 22.3 \\
\hline \multicolumn{3}{|l|}{ Employment Status } \\
\hline Self employed & 240 & 54.2 \\
\hline Private sector & 70 & 15.8 \\
\hline Public sector & 41 & 9.2 \\
\hline Unemployed & 78 & 17.6 \\
\hline Student/Apprentice & 14 & 3.2 \\
\hline
\end{tabular}

were married. Twenty-two percent of the caregivers had tertiary education: $11 \%$ had university degrees, and $11 \%$ had certificate, diploma or post-diploma qualifications. About $34 \%$ of the caregivers had secondary education and $11 \%$ had no formal education. In terms of employment status, $54 \%$ of caregivers were self-employed, $16 \%$ were working in the private sector, $9 \%$ were employed in the public sector, and 18\% were unemployed. About 3\% of the caregivers were students or apprentices.

\section{Economic costs of caregiving}

The average caregiving cost per month was US\$273.28, with indirect costs being $\$ 242.95$ and direct costs being $\$ 30.36$ (Table 4). Total cost for the study sample was $\$ 76,839.54$, with indirect costs accounting for about 
Table 4 Economic costs to caregiving for schizophrenia

\begin{tabular}{|c|c|c|c|c|c|}
\hline Cost component & $\mathrm{N}$ & Total cost ${ }^{a}$ (US\$) & Standard deviation & Cost profile $^{\mathrm{b}}(\%)$ & Average cost (US\$) \\
\hline \multicolumn{6}{|l|}{ Direct costs } \\
\hline \multicolumn{6}{|l|}{ Direct medical cost } \\
\hline Consultation & 444 & 1411.02 & 7.02 & 1.8 & 3.17 \\
\hline Drugs & 444 & 6668.49 & 22.59 & 8.7 & 15.01 \\
\hline Lab/Diagnostics & 442 & 428.20 & 5.38 & 0.5 & 0.97 \\
\hline Other & 442 & 144.64 & 4.20 & 0.2 & 0.33 \\
\hline Sub total & & 8652.36 & & 11.2 & 19.50 \\
\hline \multicolumn{6}{|c|}{ Direct non- medical costs } \\
\hline Transportation & 444 & 3675.57 & 9.62 & 4.8 & 8.28 \\
\hline Meals & 442 & 843.15 & 5.56 & 1.1 & 1.90 \\
\hline Lodging & 442 & 153.20 & 5.05 & 0.2 & 0.35 \\
\hline Miscellaneous & 442 & 142.69 & 1.20 & 0.2 & 0.33 \\
\hline Sub total & & 4814.62 & & 6.3 & 10.85 \\
\hline Total direct costs & & $13,466.97$ & & 17.5 & 30.36 \\
\hline \multicolumn{6}{|l|}{ Indirect costs } \\
\hline Formal sector & 131 & 9118.97 & 40.26 & 11.9 & 69.61 \\
\hline Informal sector & 313 & $54,253.59$ & 88.38 & 70.6 & 173.33 \\
\hline Total indirect costs & 444 & $63,372.56$ & & 82.5 & 242.95 \\
\hline Grand Total Cost & & $76,839.54$ & & 100 & 273.28 \\
\hline
\end{tabular}

aS\$ 1.00 equivalent to GHS 3.9 (Bank of Ghana average monthly interbank exchange rate, June 2016)

${ }^{b}$ Percentages computed by dividing the total cost for the item by the grand total cost and multiplying the result by 100

82.5\%. The key components of direct costs were drug (about 50\%) and transportation (27\%) costs.

\section{Intangible costs of caregiving}

The mean caregiver burden score was 16.95 (SD 8.82) out of a maximum of 48 . About $51 \%$ of the caregivers reported low burden (i.e., ZBI score of $>16$ ). The analysis also revealed that the burden in caregiving was significantly higher for females (61\%) than for males (39\%) among caregivers reporting high burden.

\section{Caregivers' quality of life}

The mean quality of life scores by domain and background characteristics are summarized in Table 5. The average overall QoL was 28.2 (SD 12.0). Average scores in the four domains were 19.6 (physical), 29.1 (psychological), 29.2 (social), and 34.8 (environmental). QoL scores across all domains were, on average, higher among males (29.6) than females (27.1) $(p<0.05)$. Caregivers who were married had higher QoL scores than those who were unmarried. The mean score across all domains increased as the caregiver's educational level increased.

\section{Predictors of costs and QoL}

The multivariate linear multiple regression results for covariates of economic cost are shown in Table 6 .
Tertiary education was significantly associated with indirect costs. Compared to those with no formal education, indirect cost for caregivers with tertiary education were lower by GHS 216 (US\$55.38, - 95\% CI: -329.41, -102.10, $p$-value $=0.0007)$. A unit increase in age, resulted in a GHS 3.3 increase in indirect cost (US\$ $0.75,95 \%$ CI: $0.99,5.52, p<0.05)$. Indirect cost for males was GHS 61.1 lower compared to females (US\$11.86, 95\% CI: $-121.77,-0.41, p<0.05)$.

With respect to predictors of ZBI score, anxiety, depression and stress were related to Zarit burden score, as presented in Table 7. The burden of caregivers with severe anxiety was approximately 4\% (95\% CI: 1.02, 6.59; $p=0.0022$ ) higher than those with no anxiety disorders, controlling for other covariates.

Table 8 shows that for a unit increase in the Zarit burden score, QoL in relation to the physical domain decreased by 0.25 (95\% CI: $-0.38,-0.13, p=0.0001)$. Similar results were obtained for the psychological QoL domains. The coefficients for the Zarit burden score, taken for all the four QoL domains together, were statistically significant $(F=5.30, p=0.0004)$. There was no statistically significant relationship between the direct and indirect cost and the four QoL domains. The QoL in relation to the physical and psychological domains was higher among caregivers who reported family support. The QoL with reference to the psychological 


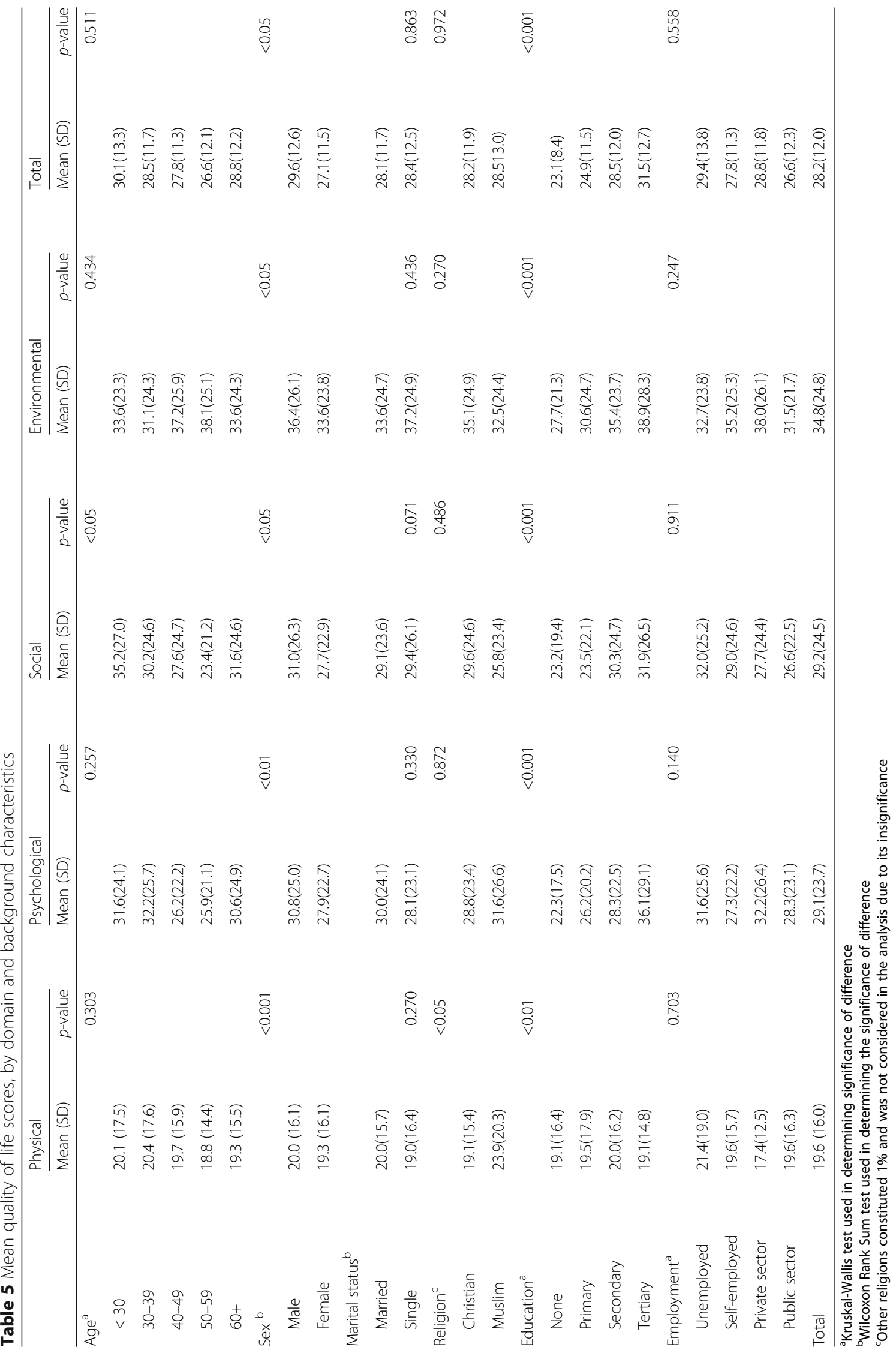


Table 6 Multivariate linear multiple regression results for covariates of economic cost

\begin{tabular}{|c|c|c|c|c|}
\hline \multirow[b]{3}{*}{ Covariates } & \multicolumn{2}{|l|}{ Cost } & & \\
\hline & \multirow{2}{*}{$\begin{array}{l}\text { Direct } \\
\beta(95 \% \mathrm{Cl})\end{array}$} & \multirow{2}{*}{$\begin{array}{l}\text { Indirect } \\
\beta(95 \% \mathrm{Cl})\end{array}$} & \multicolumn{2}{|l|}{ Joint effect } \\
\hline & & & F-test statistic & $p$-value \\
\hline & & ** & & \\
\hline & 0.71 & 3.25 & & \\
\hline Age in years & $(-0.17,1.59)$ & $(0.99,5.52)$ & 10.18 & $0.0001^{* * *}$ \\
\hline Sex & & * & & \\
\hline Female & Ref & Ref & & \\
\hline \multirow[t]{2}{*}{ Male } & 12.06 & -61.09 & 3.65 & $0.0269^{*}$ \\
\hline & $(-11.58,35.70)$ & $(-121.77,-0.41)$ & & \\
\hline \multicolumn{5}{|l|}{ Marital status } \\
\hline Single & Ref & Ref & & \\
\hline \multirow[t]{2}{*}{ Married } & 19.30 & 53.42 & 3.93 & $0.0203^{*}$ \\
\hline & $(-5.58,44.17)$ & $(-10.43,117.28)$ & & \\
\hline Proximity & * & & & \\
\hline Close & Ref & Ref & & \\
\hline \multirow[t]{2}{*}{ Far } & 32.33 & 0.84 & 2.91 & 0.0554 \\
\hline & $(5.52,59.15)$ & $(-68.00,69.67)$ & & \\
\hline Education & & $* * *$ & & \\
\hline None & Ref & Ref & & \\
\hline Primary/junior high school & $12.27(-26.56,51.11)$ & $-64.17(-163.87,35.52)$ & 18.61 & $0.0001^{* * *}$ \\
\hline Secondary & $16.19(-22.77,55.16)$ & $-79.76(-179.78,20.27)$ & & \\
\hline Tertiary & $39.84(-4.43,84.11)$ & $-215.75(-329.41,-102.10)$ & & \\
\hline Employment status & & $* * *$ & & \\
\hline None & Ref & Ref & & \\
\hline Private & $1.07(-40.83,42.96)$ & $-327.68(-435.22,-220.14)$ & & \\
\hline Public & $5.58(-41.69,52.86)$ & $-302.55(-423.91,-181.19)$ & 2.36 & 0.0953 \\
\hline Self-employed & $7.35(-25.48,40.17)$ & $-45.51(-129.79,38.76)$ & & \\
\hline Student/apprentice & $66.56(-6.26,139.38)$ & $-19.64(-206.58,167.30)$ & & \\
\hline$R^{2}$ & $50.8 \%$ & $64.2 \%$ & & \\
\hline
\end{tabular}

$\beta$ is the estimated effect of covariate; $R^{2}$ is the adjusted coefficient off determination; $\mathrm{Cl}$ is confidence interval; ref. is the reference category ${ }^{*} p<0.05,{ }^{* *} p<0.01,{ }^{* * *} p<0.001$

domain was about 3\% (95\% CI: $0.68,5.12 ; p=0.0060)$ higher for participants who reported family support compared to those that did not. Depression was associated with all the four domains of QoL $(F=19.20$, $p=0.0001)$. The QoL was $17 \%$ (95\% CI: $-22.92,-11.87$; $p$-value $=0.0001$ ) lower for participants with severe forms of depression compared to those with no depression. The results further showed that more highly educated caregivers reported higher QoL (7-15\% more) than those who were uneducated, and male caregivers reported higher QoL (2-6\% more) than female caregivers.

The results from the multiple linear regression analysis in Table 9 indicated that a unit increase in Zarit burden score reduced caregivers' QoL by 0.17
(95\% CI: $-0.28,-0.06 ; p=0.0030$ ), controlling for other covariates in the model. Overall QoL was 17\% lower for caregivers with depression compared to those with no depression.

\section{Discussion}

The aim of this study was to estimate the economic costs and QoL of family caregivers of schizophrenic patients attending three psychiatric hospitals in Ghana and to assess the factors associated with these two outcomes. The average costs incurred by caregivers amounted to approximately US\$273 per month, with about $82 \%$ of these costs being indirect costs (in terms of lost productivity). The mean caregiver burden (measured by the ZBI) was 16.95 on a scale of $0-48$, with 
Table 7 Multiple linear regression results of total caregiver burden (ZBI)

\begin{tabular}{|c|c|c|}
\hline Covariates & $\beta$ & $95 \% \mathrm{Cl}$ \\
\hline Age in years & -0.01 & $(-0.07,0.05)$ \\
\hline \multicolumn{3}{|l|}{ Sex } \\
\hline Female & Ref & \\
\hline Male & -0.42 & $(-1.89,1.05)$ \\
\hline \multicolumn{3}{|l|}{ Marital status: } \\
\hline Single & Ref & \\
\hline Married & -0.09 & $(-1.64,1.46)$ \\
\hline \multicolumn{3}{|l|}{ Proximity } \\
\hline Close & Ref & \\
\hline Far & 0.90 & $(-0.78,2.58)$ \\
\hline \multicolumn{3}{|l|}{ Education } \\
\hline None & Ref & \\
\hline Primary/junior high school & 0.10 & $(-2.34,2.55)$ \\
\hline Secondary & -4.43 & $(-2.92,2.06)$ \\
\hline Tertiary & -1.01 & $(-3.86,1.84)$ \\
\hline \multicolumn{3}{|l|}{ Employment status** } \\
\hline None & Ref & \\
\hline Private & 3.47 & $(0.74,6.19)$ \\
\hline Public & 6.09 & $(3.10,9.07)$ \\
\hline Self-employed & 1.79 & $(-0.30,3.88)$ \\
\hline Student/apprentice & 0.17 & $(-4.37,4.71)$ \\
\hline Direct cost & 0.01 & $(-0.001,0.01)$ \\
\hline Indirect cost & 0.002 & $(-0.002,0.01)$ \\
\hline Duration of care given & 0.002 & $(-0.01,0.01)$ \\
\hline Daily care given time in hours & -0.10 & $(-0.32,0.13)$ \\
\hline \multicolumn{3}{|l|}{ Other family } \\
\hline No & Ref & \\
\hline Yes & 0.42 & $(-1.03,1.87)$ \\
\hline \multicolumn{3}{|l|}{ Anxiety** } \\
\hline Normal & Ref & \\
\hline Moderate & 2.82 & $(1.05,4.59)$ \\
\hline Severe & 3.80 & $(1.02,6.59)$ \\
\hline \multicolumn{3}{|l|}{ Depression*** } \\
\hline Normal & Ref & \\
\hline Moderate & 3.24 & $(1.54,4.94)$ \\
\hline Severe & 8.25 & $(4.71,11.80)$ \\
\hline \multicolumn{3}{|l|}{ Stress*** } \\
\hline Normal & Ref & \\
\hline Moderate & 5.08 & $(2.91,7.24)$ \\
\hline Severe & 7.70 & $(4.70,10.70)$ \\
\hline$R^{2}$ & 51.9 & \\
\hline
\end{tabular}

$\beta$ is the estimated effect of covariate; $R^{2}$ is the adjusted coefficient off determination; $\mathrm{Cl}$ is confidence interval; ref. is the reference category ${ }^{*} p<0.05,{ }^{* *} p<0.01,{ }^{* * *} p<0.001$
$49 \%$ of caregivers reporting high burden. Overall, caregivers reported low QoL (28.2 out of 100).

The estimated mean monthly direct cost per month (US\$30) represented about $18 \%$ of the total cost involved in caregiving. This proportion is lower than that obtained by Addo et al. [25] (21\%) in their study on the cost of caregiving for mental illness (not schizophrenia specifically as in the current study) in Ghana. Our finding is also lower than that found by Zhai et al. [3] (33\%) in their study on the cost of caregiving for schizophrenia in China. Although Zhai et al. [3]'s study was specific to schizophrenia, differences in the study contexts may have accounted for the differences in the proportion accounted for by direct costs, implying that access to treatments and study contexts could influence the proportion of overall costs of caring for vulnerable populations. The relative contribution of direct costs to the total economic costs further implies that caregivers bear significant indirect costs which must be taken into account in efforts to ameliorate the economic burden of mental health on families.

Similar to Knock et al. [26], the current study's results demonstrate that caregivers of people with schizophrenia bear levels of other types of psychological and social burdens that are difficult to quantify. The current study found that caregivers of schizophrenics reported lower QoL compared to previous studies $[16,27]$ conducted in Chile and France. Factors such as caregiver burden and depression were associated with lower QoL, whereas support from other family members and education were associated with higher QoL. Sex was also significantly associated with QoL, with males reporting higher QoL than females. Further, $61 \%$ of caregivers who reported higher burden were females and 39\% were males. Ohaeri [28] argues that caregiving roles are primarily undertaken by female family members who bear much of the burden (e.g., psychological effect) of care in Nigeria. Similarly, Papastavrou et al. [29] found that females were more burdened than males and experienced chronic stress because of caregiving responsibilities for schizophrenics in Cyprus. Sex differences in the burden of care have also been reported in studies examining elderly care [30]. Such findings reflect broader societal realities and require more in-depth investigation.

There are limitations to the study that are worth noting. First, it was not possible to determine whether the caregiver received any assistance, in cash or in kind from other members of the family or the patient; thus, the cost burden may not be entirely attributed to the main caregiver. Second, it was not possible to conduct more nuanced analysis to assess possible 


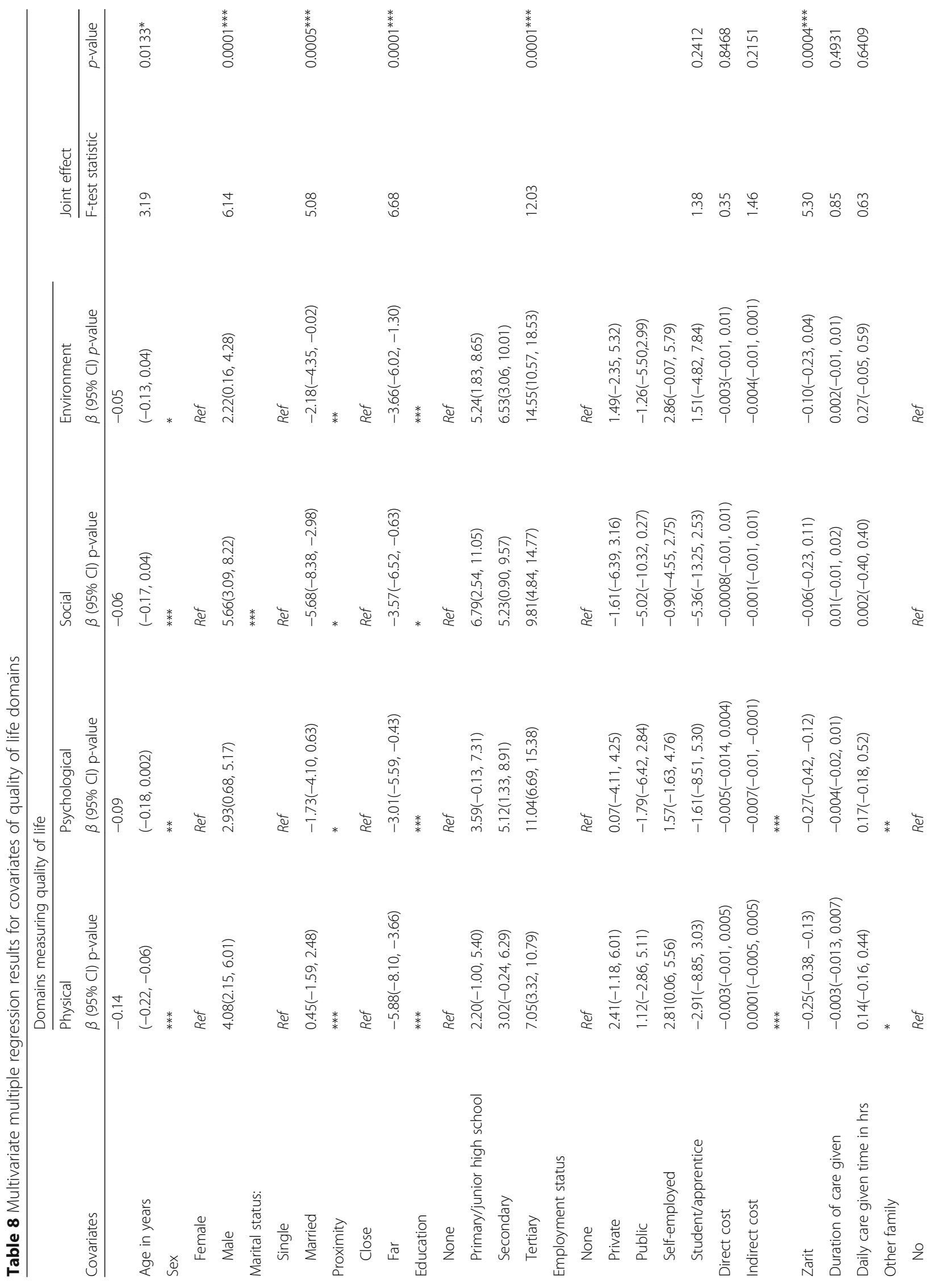




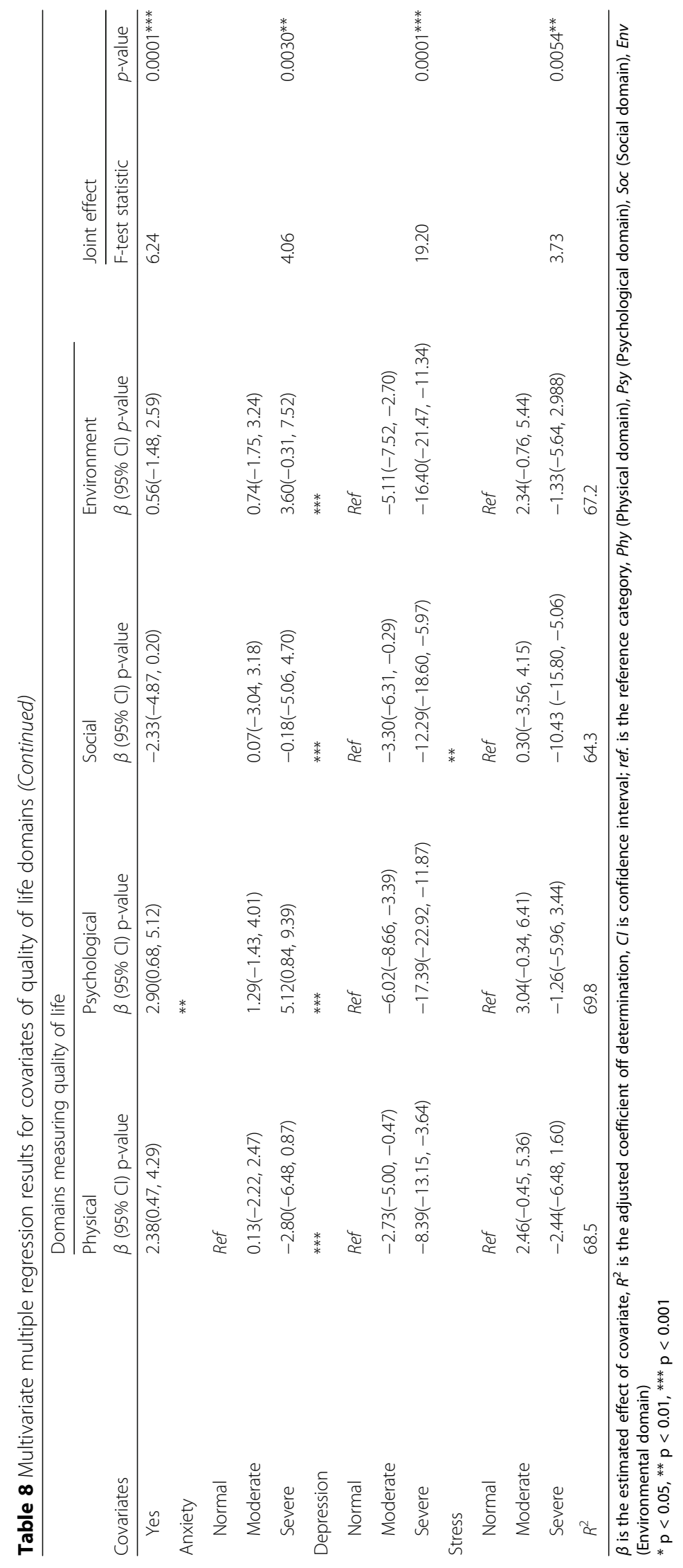


Table 9 Multiple regression results for covariates of overall quality of life

\begin{tabular}{lll}
\hline Covariates & \multicolumn{2}{l}{ Overall quality of life score } \\
\cline { 2 - 3 } & $\beta$ & $95 \% \mathrm{Cl}$ \\
\hline Age in years & -0.08 & $(-0.15,-0.1)$ \\
Sex & & \\
Female & Ref & \\
Male & 3.72 & $(1.99,5.45)$
\end{tabular}

Marital status*

$\begin{array}{lll}\text { Single } & \text { Ref } & \\ \text { Married } & -2.29 & (-4.11,-0.47) \\ \text { Proximity*** } & & \\ \text { Close } & \text { Ref } & \\ \text { Far } & -4.03 & (-6.01,-2.05)\end{array}$

Education***

None

Primary/junior high

school

Secondary

Tertiary

Ref

4.46

$(1.59,7.32)$

4.98

10.61

$(2.06,7.89)$

$(7.27,13.96)$

Employment status

$\begin{array}{ll}\text { None } & \text { Ref } \\ \text { Private } & 0.59\end{array}$

Public

Self-employed

Student/apprentice

Direct cost

Indirect cost

Zarit

Duration of care given

Daily Care given time in hours

Other family

$\begin{array}{ll}\text { No } & \text { Ref } \\ \text { Yes } & 0.88\end{array}$

Anxiety

Normal

Severe

Depression***

Normal

Severe

Stress**

Normal

Moderate
Ref

Ref

$-4.29$

$-13.62$

$(-6.32,-2.26)$

$(-17.87,-9.37)$

$(-2.63,3.81)$

$(-5.30,1.83)$

$(-0.87,4.05)$

$(-7.41,3.22)$

$(-0.01,0.004)$

$(-0.01,0.001)$

$(-0.28,-0.06)$

$(-0.01,0.01)$

$(-0.12,0.41)$

$(-0.83,2.58)$

$(-1.54,2.65)$

$(-1.85,4.72)$

Ref

2.03
Table 9 Multiple regression results for covariates of overall quality of life (Continued)

\begin{tabular}{lll}
\hline Covariates & \multicolumn{2}{l}{ Overall quality of life score } \\
\cline { 2 - 3 } & $\beta$ & $95 \% \mathrm{Cl}$ \\
\hline Severe & -3.87 & $(-7.48,-0.25)$ \\
$R^{2}$ & 70.1 & \\
\hline
\end{tabular}

$\beta$ is the estimated effect of covariate, $R^{2}$ is the adjusted coefficient off determination, $C l$ is confidence interval, ref. is the reference category ${ }^{*} p<0.05,{ }^{* *} p<0.01,{ }^{* * *} p<0.001$

underlying reasons (e.g., coping styles) for some of the differences observed. Nonetheless, the current study adds to the sparse literature on the economic and social costs of mental disorders in sub-Saharan Africa.

\section{Conclusions}

The study findings highlight the significant burden of caring for people with schizophrenia on family caregivers in Ghana. As the country considers deinstitutionalizing mental health care, it is important that measures to alleviate the direct costs on caregivers are taken into account. Currently, the National Health Insurance Scheme (NHIS) does not cover services for schizophrenia or other mental disorder, deepening the burden of families. One possible avenue to alleviate the costs incurred by caregivers of people with mental illness would be to extend social protection programs, such as the Livelihood Empowerment Against Poverty (LEAP) program (which provides cash transfers to vulnerable groups), to caregivers to cushion the effects of the shocks of the direct costs. Study findings also underscore the significant non-quantifiable burdens, such as emotional stress, that are borne by caregivers and that affect their quality of life. The quality of life of caregivers of patients with mental disorders should be considered in health policies related to mental illness.

\section{Abbreviations}

DALYs: Disability-adjusted life-years; DASS: Depression anxiety stress scale; GHS: Ghanaian Cedi; ICD-10: International Classification of Disease, $10^{\text {th }}$ edition; LEAP: Livelihood empowerment against poverty; LMICs: Low and middle income countries; NHIS: National Health Insurance Scheme; PPS: Probability proportionate to size; QoL: Quality of Life; UK: United Kingdom; US\$: United States Dollar; WHO: World Health Organisation; WHOQOL: WHO Quality of Life; WHOQOL-BREF: abridged WHO Quality of Life; YLD: Years lived with disability; ZBI: Zarit Burden Interview

\section{Acknowledgements}

The authors acknowledge the following for their support in implementing the study: Joseph Osafo and Gloria Odue, both at the Psychology Department, University of Ghana; the Mental Health Authority of Ghana; and the management and staff of the study facilities. The authors also thank all the study participants.

\section{Funding}

This research was funded by an African Doctoral Dissertation Research Fellowship (ADDRF) re-entry grant award to JN and IAK offered by the 
African Population and Health Research Center (APHRC) in partnership with the International Development Research Centre (IDRC). Publication was funded by the International Development Research Center (Grant Number 107508-001) and the John D. and Catherine T. MacArthur Foundation (Grant Number 14-107495-000-INP).

\section{Availability of data and materials}

Data supporting the findings of the study will be made available upon request.

\section{About this supplement}

This article has been published as part of BMC Health Services Research Volume 17 Supplement 2, 2017: Research for health systems strengthening in Africa: studies by fellows of the African Doctoral Dissertation Research Fellowship (ADDRF) program. The full contents of the supplement are available online at https://bmchealthservres.biomedcentral.com/articles/ supplements/volume-17-supplement-2.

\section{Authors' contributions}

JN and IAK conceived the study. YNOB, GCA, SAA, SD, DD, YT, MA contributed to design of the study and data collection.. YNOB led the collection of data. YNOB, JN, IAK, DD, SAA, GCA, MA contributed to analysis and interpretation of results. YNOB and JN drafted the manuscript. The manuscript was reviewed by all the authors for intellectual content. The final version of the manuscript was approved by all authors.

\section{Ethics approval and consent to participate}

Ethical approval for the study was granted by the Ghana Health Service Ethical Review Committee.

\section{Consent for publication}

Not applicable

\section{Competing interests}

The authors declare that they have no competing interests.

\section{Publisher's Note}

Springer Nature remains neutral with regard to jurisdictional claims in published maps and institutional affiliations.

\section{Author details}

${ }^{1}$ National Health Insurance Authority, Accra, Ghana. ${ }^{2}$ Department of Pharmacy Practice and Clinical Pharmacy, School of Pharmacy, College of Health Sciences, University of Ghana, Legon, Ghana. ${ }^{3}$ Department of Health Policy, Planning and Management, School of Public Health, College of Health Sciences, University of Ghana, Legon, Ghana. ${ }^{4}$ Department of Biostatistics, School of Public Health, College of Health Sciences, University of Ghana, Legon, Ghana. ${ }^{5}$ Pantang Psychiatric Hospital, Accra, Ghana. ${ }^{6}$ College of Global Public Health, New York University, New York, NY, USA.

\section{Published: 4 December 2017}

\section{References}

1. Vigo D, Thornicroft G, Atun R. Estimating the true global burden of mental illness. Lancet Psychiatry. 2016:3(2):171-8.

2. WHO. Burden of mental and behavioural disorders. The world health report 2001-mental health: new understanding, new hope. Geneva: World Health Organisation; 2001

3. Zhai J, Guo X, Chen M, Zhao J, Su Z. An investigation of economic costs of schizophrenia in two areas of China. Int J Ment Health Syst. 2013;7(1):26.

4. WHO. Mental disorders. Geneva: Switzerland World Health Organisation; 2016.

5. WHO: WHO-AIMS report on mental health system in Ghana. Geneva: World Health Organization; 2011.

6. WHO. Integrating mental health into primary care: a global perspective. Geneva: World Health Organization; 2008.

7. Sariah $A E$, Outwater AH, Malima Kl. Risk and protective factors for relapse among individuals with schizophrenia: a qualitative study in Dar es Salaam, Tanzania. BMC Psychiatry. 2014;14(1):240.

8. Basheer S, Niazi RS, Minhas FA, Najam N. Depression and anxiety in the caregivers of mentally ill patients. J Pak Psychiatr Soc. 2005;2(1):27.
9. Bevans MF, Sternberg EM. Caregiving burden, stress, and health effects among family caregivers of adult cancer patients. JAMA. 2012; 307(4):398-403

10. Dwyer JW, Lee GR, Jankowski TB. Reciprocity, elder satisfaction, and caregiver stress and burden: the exchange of aid in the family caregiving relationship. J Marriage Fam. 1994;56(1):35-43.

11. Knapp M, Mangalore R, Simon J. The global costs of schizophrenia. Schizophr Bull. 2004;30(2):279-93.

12. Kreisman $D E$, Joy VD. Family response to the mental illness of a relative: a review of the literature. Schizophr Bull. 1974;10:34-57.

13. Robison J, Fortinsky R, Kleppinger A, Shugrue N, Porter M. A broader view of family caregiving: effects of caregiving and caregiver conditions on depressive symptoms, health, work, and social isolation. J Gerontol B Psychol Sci Soc Sci. 2009;64(6):788-98.

14. Salama RAA, El-Soud FAA. Caregiver burden from caring for impaired elderly: a cross sectional study in rural lower Egypt. Ital J Public Health. 2012;9(4). doi: http://dx.doi.org/10.2427/8662.

15. Yusuf AJ, Nuhu FT, Akinbiyi A. Caregiver burden among relatives of patients with schizophrenia in Katsina, Nigeria. S Afr J Psychiatr. 2009;15(2).

16. Margetic BA, Jakovljevic M, Furjan Z, Margetic B, Marsanic VB. Quality of life of key caregivers of schizophrenia patients and association with kinship. Cent Eur J Public Health. 2013:21(4):220-3.

17. Rawat P. Poster \#M258 Quality of life and depression among caregivers of schizophrenics. Schizophr Res. 2014;153(Supplement 1):S283-S85.

18. GSS. Population and housing census 2010: summary report of final results. Ghana Statistical Service: Accra; 2012

19. Cochran WG. Sampling techniques. 2nd ed. New York: John Whiley and Sons Inc; 1963.

20. Bédard M, Molloy DW, Squire L, Dubois S, Lever JA, O'Donnell M. The zarit burden interview: a new short version and screening version. Gerontologist. 2001;41(5):652-7.

21. The WHOQOL Group. Whogol-Bref: introduction, administration, scoring and generic gersion of the assessment. Programme on Mental Health. 1996:16:1-12.

22. Bland JM, Altman DG. Statistics notes: Cronbach's alpha. BMJ. 1997; 314(7080):572

23. MacKenzie SB, Podsakoff PM, Podsakoff NP. Construct measurement and validation procedures in MIS and behavioral research: integrating new and existing techniques. MIS Q. 2011;35(2):293-334.

24. Nunnally JC, Bernstein I. Psychometric therapy. New York: McGraw-Hill; 1994

25. Addo R, Nonvignon J, Aikins M. Household costs of mental health care in Ghana. J Ment Health Policy Econ. 2013;16(4):151-9.

26. Knock J, Kline E, Schiffman J, Maynard A, Reeves G. Burdens and difficulties experienced by caregivers of children and adolescents with schizophreniaspectrum disorders: a qualitative study. Early Interv Psychiatry. 2011;5(4):349-54.

27. Boyer L, Caqueo-Urízar A, Richieri R, Lancon C, Gutiérrez-Maldonado J, Auquier P. Quality of life among caregivers of patients with schizophrenia: a cross-cultural comparison of Chilean and French families. BMC Fam Pract. 2012;13(1):42.

28. Ohaeri JU. Caregiver burden and psychotic patients' perception of social support in a Nigerian setting. Soc Psychiatry Psychiatr Epidemiol. 2001;36(2):86-93.

29. Papastavrou E, Charalambous A, Tsangari H, Karayiannis G. The cost of caring: the relative with schizophrenia. Scand J Caring Sci. 2010;24(4):817-23.

30. Nortey ST, Aryeetey GC, Aikins M, Amendah D, Nonvignon J. Economic burden of family caregiving for elderly population in southern Ghana: the case of a peri-urban district. Int J Equity Health. 2017;16(1):16

\section{Submit your next manuscript to BioMed Central} and we will help you at every step:

- We accept pre-submission inquiries

- Our selector tool helps you to find the most relevant journal

- We provide round the clock customer support

- Convenient online submission

- Thorough peer review

- Inclusion in PubMed and all major indexing services

- Maximum visibility for your research

Submit your manuscript at www.biomedcentral.com/submit
BioMed Central 